Revue d'histoire du XIXe siècle

Société d'histoire de la révolution de 1848 et des

révolutions du XIXe siècle

23 | 2001

Nouvelles approches en histoire économique

\title{
Waterloo dans la mémoire des Français (1815-1914). Thèse de doctorat en histoire
}

Sous la direction de Claude-Isabelle Brelot, Université Lumière-Lyon 2, 3 volumes, $782 \mathrm{f}^{\circ}, 10$ janvier 2000, jury constitué de Claude-Isabelle Brelot, Jean El Gammal (rapporteur), Philippe Joutard, Pierre Laborie, Jean-Luc Mayaud (président) et Robert Tombs, mention très honorable et félicitations du jury à l'unanimité.

Jean-Marc Largeaud

\section{OpenEdition}

\section{Journals}

Édition électronique

URL : http://journals.openedition.org/rh19/345

DOI : $10.4000 /$ rh 19.345

ISSN : $1777-5329$

Éditeur

La Société de 1848

Édition imprimée

Date de publication : 1 décembre 2001

Pagination : 310-312

ISSN : 1265-1354

Référence électronique

Jean-Marc Largeaud, «Waterloo dans la mémoire des Français (1815-1914). Thèse de doctorat en histoire », Revue d'histoire du XIXe siècle [En ligne], 23 | 2001, mis en ligne le 15 octobre 2002, consulté le 03 mai 2019. URL : http://journals.openedition.org/rh19/345 ; DOI : 10.4000/rh19.345

Ce document a été généré automatiquement le 3 mai 2019.

Tous droits réservés 


\section{Waterloo dans la mémoire des Français (1815-1914). Thèse de doctorat en histoire}

Sous la direction de Claude-Isabelle Brelot, Université Lumière-Lyon 2, 3 volumes, $782 \mathrm{fo}, 10$ janvier 2000, jury constitué de Claude-Isabelle Brelot, Jean El Gammal (rapporteur), Philippe Joutard, Pierre Laborie, Jean-Luc Mayaud (président) et Robert Tombs, mention très honorable et félicitations du jury à l'unanimité.

Jean-Marc Largeaud

L'histoire de la mémoire de Waterloo développe un point de vue particulier par rapport à l'ensemble des travaux d'histoire plus attentifs aux défaites politiques du XIX ${ }^{\mathrm{e}}$ siècle. Le processus de mémoire est plus complexe que la construction de la mémoire républicaine étudiée par Pierre Nora dans les Lieux de mémoire. Le mécanisme est mixte, positif et négatif, puisque la défaite est douloureuse mais glorieuse et insérée positivement dans la mémoire nationale.

Menée sur le long terme, la recherche a été conduite en fonction de trois axes problématiques. Le premier impliquait la construction de la mémoire et la notion de "lieu de mémoire". Il a fallu tenir compte d'une part de la façon dont pouvait se constituer la mémoire d'un événement, par le repérage des groupes sociaux ou politiques impliqués, par la place donnée à la bataille dans les mémoires collectives et individuelles, par l'interrogation sur la distinction à opérer entre traumatisme et reconstruction de la mémoire. D'autre part, il fallait se demander si Waterloo était un "lieu de mémoire" de la Nation française nourrissant une identité et une vérité symbolique. Le second axe a pris en compte la guerre et la défaite. S'il a paru nécessaire d'étudier la guerre davantage en fonction des représentations que des réalités, la notion de défaite justifiait deux interrogations complémentaires sur l'expression de "défaite glorieuse" et sur l'existence ou non d'une culture de la défaite. Le troisième a été nourri par les interrogations sur la Nation et le "phénomène national", sur les rapports d'une défaite nationale avec l'imaginaire social, sur la genèse et l'évolution d'émotions qualifiées de "nationales". 
L'ensemble des sources est fondamentalement hétérogène : documents militaires, stratification et diversité de l'histoire Française du XIX siècle, presse, littérature et iconographie. Pour retrouver les mécanismes de sédimentation de la mémoire, l'accent a été mis sur les appropriations diverses et autant que possible sur la diffusion des thèmes associés à Waterloo. L'écart entre les explications qualitatives et les analyses quantitatives reste important mais inévitable. Il fait courir cependant trois risques : une évaluation contestable de la profondeur de l'imprégnation de l'événement, une surinterprétation des documents, la surévaluation du poids des sources culturelles. Le côté fragmentaire de la documentation accentue ces difficultés. Les résultats de la recherche paraissent en premier lieu prouver la réalité d'un phénomène de mémoire relatif à Waterloo. Dans les rapports avec "1815", Waterloo se situe plutôt du coté d'une mémoire reconstruite que de celle d'un traumatisme vécu. Mais, en termes de diffusion, les réponses sont décevantes pour la production culturelle (livres, etc.) comme pour la distribution dans le corps social. En second lieu, l'instrumentalisation de la bataille a montré l'extension de Waterloo comme argument d'opposition politique formulé par toutes les familles politiques (libéraux, républicains, royalistes, nationalistes de la fin du siècle) et aussi par diverses catégories de marginaux et d'exclus. Se dessinent ainsi plusieurs manières d'assumer la défaite et un rôle limité mais universel de la bataille comme instrument de disqualification politique. Face à cette argumentation, les pouvoirs ont usé de la répression et de réponses symboliques. L'accent a été mis sur l'utilisation de la notion de "patrie" sous Louis XVIII, sur l'usage de la mémoire de Napoléon et la création de la continuité de la "défaite glorieuse" sous la monarchie de Juillet, sur l'instrumentalisation de la légende napoléonienne sous Napoléon III, sur les choix de la III ${ }^{e}$ République de conserver à la bataille une place importante dans la pédagogie républicaine. Waterloo semble constituer un exemple de la manière dont se construit, par appropriations croisées, une mémoire collective nationale. Enfin, la thèse a tenté de montrer les ressorts d'une mémoire sans lieu. La mémoire est en effet reconstruite en fonction de plusieurs facteurs, relation à Napoléon et à la légende, à la Révolution. Elle est aussi fonction d'une culture de la guerre où Waterloo dévoile les illusions, mais aussi les réalités des servitudes du combat. En ce sens, Waterloo est un cas à part et un cas limite dans les représentations de la guerre, peut-être parce qu'il s'agit d'une défaite. Dans cette culture de la guerre, la construction de l'héroïsme joue un rôle central, car pluriel dans ses connotations idéologiques ; libérales, républicaines, catholiques... Le dernier des ressorts de la mémoire réside dans la tension entre identités personnelles et identités collectives. Un fait de mentalité permet à diverses catégories de vaincus de s'emparer de Waterloo. Penser avec, contre où grâce à Waterloo d'autres défaites révèle bien une culture de la défaite. Elle se décline dans la manière dont Waterloo devient une forme d'expression de soi et dans les productions qui font de la littérature le lieu véritable de cette mémoire. Victor Hugo donne ainsi la version la plus complète d'un mythe : un récit semi-fabuleux, une explication de la défaite, une fonction de mobilisation républicaine.

En définitive, l'apport du travail réside dans la reconstitution d'une mémoire sans commémoration, dans la démonstration de la généalogie de la défaite glorieuse qui fait de Waterloo un élément du sentiment national français et un élément de la conscience nationale républicaine, dans l'émergence, les variations et les leçons ambiguës d'une culture de la défaite. Il faudrait maintenant ouvrir la recherche sur la mémoire des autres pays belligérants pour analyser ce qui est sans doute une des dates de la symbolique identitaire de l'Europe et peut-être un lieu de mémoire européen. 
INDEX

Mots-clés : Histoire politique, Représentations, Napoléon III, Histoire culturelle, Mémoire 